\title{
A interculturalidade no ensino-aprendizagem de português como língua estrangeira em ambiente de imersão: um estudo de caso
}

\author{
Fernanda Ricardo Campos \\ Jerônimo Coura-Sobrinho \\ Rose Mara Silva \\ Centro Federal de Educação Tecnológica de Minas Gerais - CEFET-MG
}

\begin{abstract}
Resumo
O objetivo deste artigo é refletir sobre o papel da cultura e da (inter) culturalidade no ensino de português como LE em um ambiente de imersão, através da experiência das autoras com um grupo de estudantes da República Dominicana e Haiti, em Belo Horizonte - MG, Brasil. Para alcançar tal objetivo, este trabalho apresenta um estudo de caso de caráter qualitativo, em que as tarefas e atividades realizadas dentro e fora de sala foram estudadas à luz dos conceitos teóricos da abordagem intercultural e aspectos identitários no ensino de Português Língua Estrangeira (PLE), baseado nos trabalhos de Júdice (2005), Trouche (2005), Kramsch (2008), Schoffen (2012), Mendes (2015), entre outros. As percepções das autoras e dos aprendizes a respeito das aulas também são discutidas através das respostas dos alunos, relatadas em um questionário sobre o curso de língua portuguesa e cultura brasileira realizado no primeiro semestre de 2015.
\end{abstract}

Palavras-chave: Português como língua estrangeira. Abordagem intercultural. Ambiente de imersão.

\begin{abstract}
This article aims to reflect on the role of culture and (inter) culturalism in Portuguese teaching as FL in an immersive environment, based on the authors' experience with a group of students from the Dominican Republic and Haiti, in Belo Horizonte, MG, Brazil. To achieve this goal, this paper presents a qualitative case study in which tasks and activities given inside and outside of the classroom were studied in the light of theoretical concepts such as the intercultural approach and identity aspects in teaching Portuguese as a Foreign Language (PFL). The theoretical base came from the works of Júdice (2005), Trouche (2005), Kramsch (2008), Schoffen (2012), and Mendes (2015), among others. The authors' and the students' perceptions about the classes are also discussed using their answers to a questionnaire about the course of Portuguese language and Brazilian culture that was offered in the first semester of 2015.
\end{abstract}

Keywords: Portuguese as a foreign language. Intercultural approach. Immersion environment. 


\section{INTRODUÇÃO}

O presente relato apresenta um estudo sobre o ensino de PLE através de uma abordagem interculturalista. A compreensão de que a cultura põe em evidência aquilo que somos e a maneira como usamos a língua pode ser um fator importante e diferenciador no contato com o aprendiz de Português Língua Estrangeira (PLE). Sabemos que a língua em si, como signo, não reflete uma cultura. Desta forma, dentre outros conceitos sobre cultura que abordaremos na próxima seção, destacamos aqui a visão de Trouche (2005) que entende cultura como "um sistema de crenças e valores e uma organização sociopolítica que configuram um modo de agir e interagir, de fazer, de dizer e de comportar-se de uma dada sociedade" (p. 69), ou seja, é a junção da "experiência comum" com a "experiência refletida'. Assim, a autora deixa claro que língua, sociedade e cultura são indissociáveis e complementares entre si, pois "da língua participam a história e a cultura que a constituem e de que ela é ao mesmo tempo produtora" (Ibid, p. 70).

Ao recebermos o convite para trabalhar com o Módulo Cultura, no Curso Intensivo de Língua Portuguesa e Cultura Brasileira para Estrangeiros, realizado no $2^{\circ}$ semestre de 2015, no Centro Federal de Educação Tecnológica de Minas Gerais - CEFET-MG, em Belo Horizonte, percebemos que precisávamos trabalhar os conteúdos linguísticos dentro da comunidade local e além do ambiente da sala de aula, com tarefas comunicativas que levassem os alunos a refletir não só sobre a cultura brasileira e mineira, mas, também, sobre a cultura de seus países de origem, possibilitando uma percepção diferenciada de si próprios e do outro. Começamos, assim, a refletir sobre experiências anteriores, aulas ministradas em outros semestres do Módulo Cultura, e a repensar o curso para os alunos que chegariam da República Dominicana e Haiti, em Belo Horizonte, para o primeiro curso intensivo de verão oferecido pelo CEFET-MG. O nosso objetivo era o de aprimorar o conhecimento da língua portuguesa e da cultura brasileira.

Ao receber da coordenação os cinco temas norteadores do curso: (i) sociedade/personalidades; (ii) comércio e transporte; (iii) literatura, música, gastronomia; (iv) regiões do Brasil (características geográficas, sociais, linguísticas) e (v) Brasil atual (tecnologia, educação, saúde), começamos a nos questionar e ponderar, dentre outros aspectos, sobre como devem ser as aulas de cultura num ambiente de imersão. O que se deve privilegiar? O que esses alunos buscavam conhecer e aprender no Brasil? Qual o interesse imediato desses aprendizes? 
Sendo assim, levando em conta essa experiência, nossa intenção neste estudo é refletir sobre o papel do ensino de cultura em um ambiente de imersão, na comunidade local. Para isso, pretendemos rever e refletir sobre as tarefas e atividades realizadas com esse grupo dentro e fora de sala de aula, tendo como embasamento teórico a abordagem intercultural e os aspectos identitários no ensino de PLE, baseado em trabalhos da área como Júdice (2005), Trouche (2005), Kramsch (2008), Leroy (2011), Schoffen (2012), Mendes (2015), entre outros. Nossa percepção das aulas e a visão dos alunos também são apresentadas de acordo com as respostas dos mesmos ao questionário elaborado pelas autoras e disponibilizado online.

\section{CULTURA E INTERCULTURALIDADE: CONCEPÇÕES TEÓRICAS}

Esta seção se propõe a apresentar os conceitos de língua, cultura e interculturalidade baseado em pesquisas da área, destacando a visão de alguns autores renomados.

Hymes (1972) afirma que "toda língua está profundamente vinculada à cultura que expressa e transmite, sendo impossível dissocia-las" (apud. Ferreira, 1998, p. 39).

Schoffen (2012) destaca que cultura diz respeito às "bases do significado" de um povo, às suas atitudes e crenças, formas de perceber, lembrar, agir e avaliar as ações dos outros, compartilhadas por membros de determinada comunidade de fala (p. 20). Assim, envolve a reflexão do aluno sobre as práticas sociais da cultura alvo em comparação com a sua própria, desmistificando estereótipos e sem julgamentos de valores. Portanto, compreendemos a cultura do outro ao compreendermos primeiramente a nossa e vice-versa e, de acordo com a autora, este é o "primeiro estágio da compreensão intercultural”, assim, cabe ao professor despertar essa percepção de interculturalidade no aluno, levando-o a saber como lidar ou agir dentro de uma outra cultura, interagindo com seus interlocutores na língua alvo.

Mendes (2015, p. 207) faz um breve histórico sobre as várias definições do termo 'cultura', na visão da antropologia e da sociologia, como conceito científico, desde o século XIX até os dias de hoje. Dentro da antropologia ela destaca alguns autores, entre eles Tylor (1832-1917), que formulou a primeira definição de cultura. De acordo com a tradição antropológica, a cultura é definida como a totalidade de características de um 
grupo social específico, como suas crenças, valores ou costumes.

No entanto, no século 20, autores renomados como Franz Boas, Wissler, Alfred Kroeber, Margareth Mead, Felix Keesing, Marshal Sahlins, refutaram essas teorias, destacando que "é possível e comum existirem diferenças culturais muito grandes entre os povos que habitam o mesmo ambiente físico, e que não existe correlação significativa entre as características genéticas dos diferentes grupos e o seu comportamento cultural" (LARAIA, 1999. apud. MENDES, 2015, p. 208). E Cuche (1999, p.140) defende a visão de que não existe uma cultura "pura", mas toda cultura é "mista", pois está em constante contato com outras e diversas culturas a todo o momento (apud. MENDES, 2015, p. 210).

Geertz (1978), outro autor antropólogo destacado por Mendes (2015, p. 211), possui uma visão semiótica da cultura. Ele comenta que "quando se compreende a cultura do outro, o que antes era opacidade transforma-se em entendimento; o que era 'estranho' passa a ser compreensível dentro do quadro de referência que tomamos em consideração". No entanto, estar e conviver em outra cultura não significa agir como um nativo, mas dialogar com o outro se fazendo entender e ao mesmo tempo entender a forma de agir ou pensar do outro.

Finalmente, na visão sociológica, é destacado, pela autora, o trabalho de Simon Schwartzman (1997) que entende a cultura como "conjunto de conceitos e elementos que caracterizam a vida em sociedade", ou seja, a organização social e a interação entre os indivíduos na sua vida familiar, a divisão do trabalho e a ocupação e defesa do espaço e território. Desta forma, Mendes (2015) conclui que:

A cultura [...] não pode ser vista como superestrutura, como conteúdo a ser aprendido ou como conjunto de informações sobre um país ou grupo social. Antes, deve ser compreendida como matriz simbólica, como rede de significados que vamos compondo à medida que vivemos e interagimos com outros. A partir dessa compreensão, as ações que desenvolvemos em sala de aula devem ser voltadas para ensinar os nossos alunos não a gramática fria e estanque, mas modos de ser e de viver em português (p. 219).

Entendemos que a compreensão deste "viver em português" e o entendimento do (novo) lugar do aprendiz começam a fazer parte da língua desse falante, e é à luz dessa perspectiva de cultura de Mendes (2015) que desenvolvemos nosso trabalho.

Ferreira (1998) afirma que adquirir uma nova língua presume a assimilação de uma nova cultura para que haja uma comunicação e compreensão eficientes entre os interlocutores de diferentes países. A autora adota a visão de cultura como "o conjunto de 
manifestações da vida de um povo", e isso engloba "todas as atividades do fazer e do pesar humano" (p. 40). Para a autora, em um ensino intercultural eficaz de PLE, o aprendiz é levado a refletir sobre sua própria língua e cultura maternas para que, a partir daí, entenda melhor a língua e a cultura estrangeira. A tarefa de comparar e estar em constante conflito com a nova cultura faz com que o aprendiz desenvolva a criticidade, ajudando-o a aceitar o diferente, impedindo, assim, que "estereótipos negativos dificultem a verdadeira compreensão entre as culturas" (Ibid. p. 45).

Sabendo que nossos alunos eram falantes de espanhol, sabíamos que o ensino de PLE tornar-se-ia peculiar se comparado com o ensino para falantes de outros idiomas, pois, teoricamente, o processo intercultural é mais próximo. Sendo assim, ajudar o aluno a reconhecer o que há de igual e o que há de diferente na língua e cultura alvo ajuda-o a evoluir de forma mais rápida na aquisição da LE. Como afirma Ferreira (1998), o grande desafio do professor é construir de forma conjunta e intercultural com o aluno um aprendizado que desperte seu senso crítico e faça-o crescer como pessoa de maneira integral, para que possa através do conhecimento transformar-se e transformar, também, o que o cerca. Com esta visão, entendemos, como professores de PLE, que é necessário ensinar os aprendizes a 'viverem em outra cultura', em uma situação de imersão, utilizando a língua como primeiro suporte para o entendimento desta cultura alvo. Como destaca Mendes (2015) "ao ensinarmos língua, estamos ensinando uma língua-cultura" (p. 218).

Portanto, o professor de PLE, principalmente aquele que trabalha em ambiente de imersão, tem um duplo papel: o de docente e o de interculturalista. Assim, entendendo que a identidade cultural é construída na interação, dentro desse contexto deve-se introduzir o multiculturalismo no ensino de uma LE, ou seja, enxergar a sala de aula como espaço de diálogo entre as culturas, onde há a valorização do discurso do professor e do aluno.

\section{PERFIL DOS ALUNOS}

O Curso Intensivo de Língua Portuguesa e Cultura Brasileira para Estrangeiros, realizado no $2^{\circ}$ semestre de 2015, no CEFET/MG, em Belo Horizonte, Brasil foi idealizado tendo em vista um público alvo específico, a saber, 6 (seis) alunos da República Dominicana e 1 (uma) aluna do Haiti. Com exceção da haitiana, que tem o francês como língua materna, os alunos são hispanófonos. Todos pertencem à mesma faixa etária, entre 
25 a 30 anos, possuem curso de graduação já concluído, são falantes de outras línguas, como o inglês, além de terem estudado em outros países. Além disso, todos eles são alunos do Centro Cultural do Brasil na República Dominicana, portanto, antes de desembarcarem ao Brasil para um curso de imersão, já possuíam o nível intermediário na língua portuguesa.

\section{O curso Intensivo de Língua Portuguesa e Cultura Brasileira para Estrangeiros}

A instituição CEFET-MG, em Belo Horizonte, possui um grupo de pesquisa, há alguns anos, na área de PLE, e oferece ainda, por meio de projetos de extensão, cursos para alunos estrangeiros e cursos de formação para professores e comunidade acadêmica que pretendem ingressar na área. Este curso foi um projeto-piloto, primeiro acordo entre instituições brasileiras e internacionais, concebido para um público específico e homogêneo - no sentido de pertencerem a um mesmo país, uma mesma cultura. O Curso Intensivo de Língua Portuguesa e Cultura Brasileira para Estrangeiros contou com uma carga horária de 75 horas - divididos em 45 horas dos módulos língua, cultura e produção de texto e 30 horas de atividades de campo/passeios. As 45 horas em sala de aula compreenderam 15 encontros, ou seja, 5 aulas com a duração de 3 horas cada uma para cada um dos três módulos: o (i) Módulo Língua, em que se privilegiou o ensino de gramática e vocabulário; o (ii) Módulo de Produção Textual, em que se trabalhou a leitura, a interpretação e a produção de textos e o (iii) Módulo Cultura, com o objetivo de trabalhar a cultura belo-horizontina e a cultura mineira, bem como a brasileira.

Ao sermos designadas para ofertar o Módulo Cultura, buscamos um maior conhecimento do perfil e objetivo dos alunos que viriam fazer o curso. Como seriam poucas aulas selecionamos atividades e tarefas a serem realizadas alternadamente no espaço físico de sala de aula, e em diferentes locais da cidade, além de passeios a museus, visitas a outras cidades, etc.

Nosso objetivo maior, ao planejarmos as aulas, era levar o aluno a perceber in loco os diferentes comportamentos, formas de pensar e agir dos belo-horizontinos. Durante o curso tentamos fazer com que percebessem a diversidade cultural do Brasil em sua enorme extensão territorial e, com a visão de uma cultura que envolve contextos situados, deixar claro essa heterogeneidade e a noção de que as inúmeras formas de comportamentos para determinadas situações não só variam de região para região, mas de cidade para cidade e 
que, mesmo dentro da própria Belo Horizonte, não se pode definir uma única cultura compartilhada entre os moradores, variando, assim, de comunidade para comunidade.

Pesquisamos várias atividades do Portal do Professor de Português Língua Estrangeira - PPPLE - e adaptamos a maior parte, conscientes de que era um grupo específico e com um propósito específico. Finalmente, introduzimos tarefas e atividades pensadas e elaboradas por nós de acordo com os temas propostos. A seguir, comentamos a respeito de cada aula, das tarefas e atividades ministradas, para em seguida discorrer sobre a percepção dos alunos e das autoras a respeito do Módulo Cultura, à luz da abordagem intercultural.

\section{Instrumento de Coleta de Dados}

A coleta de dados foi feita por meio de um questionário, confeccionado para a pesquisa com base no curso ofertado, de maneira a nortear essa coleta sem se desviar do objetivo proposto. Foram elaboradas dez perguntas, que vão desde a percepção dos alunos sobre o curso em si, até sua opinião sobre o Brasil e seu povo, bem como o que gostariam de ver em outro possível curso. Dos sete alunos que fizeram o curso, cinco foram os respondentes, os quais redigiram em bom português.

O questionário foi viabilizado por e-mail, em formato online, a fim de servir como instrumento para esta coleta de dados com os aprendizes e está disponibilizado em https://docs.google.com/forms/d/16L31xi42pn83QpwqMzEDs1s0kaVnmvPu14EmE8164a $\underline{0 / v i e w f o r m}$. Cinco dos sete alunos responderam ao questionário e suas respostas serviram como base para este estudo das aulas e/ou atividades do Módulo Cultura, ministrado por nós.

\section{ESTUDO DAS AULAS: A INTERCULTURALIDADE EM FOCO}

Nesta seção são relatadas as tarefas e atividades realizadas no Módulo Cultura, verificando a presença da interculturalidade no ensino de PLE, que é o objetivo deste artigo.

Segundo Júdice (2005) é preciso saber como criar atividades ou tarefas que proporcionem interação entre os alunos e entre aluno-professor. A autora defende, ainda, que o material a ser trabalhado deve ser autêntico e de acordo com o perfil da turma e de seu interesse. Por isso há a necessidade de conhecimento prévio do perfil dos alunos. 
Entendemos que materiais autênticos são aqueles desenvolvidos para alcançar um propósito social na comunidade linguística em que foram produzidos. (ANDRIGHETTI \& SCHOFFEN, 2012, p. 26). E para fazer a seleção de abordagens adequadas de tarefas a serem utilizadas em sala de aula é necessário que o professor tenha "clareza do perfil da turma, dos objetivos gerais do curso e dos objetivos específicos que nortearão a elaboração de cada tarefa" (JÚDICE, 2005, p.49). Para Kramsch (2008), autenticidade cultural referese à maneira em que a língua é usada em uma comunicação natural, não pedagógica (p. 177).

Assim sendo, elaboramos a primeira aula baseando-nos nas informações sobre o grupo de alunos e, dentro do tema proposto, com o objetivo de proporcionar o reconhecimento imediato de estereótipos e a discussão de aspectos culturais relacionados a costumes, hábitos e modos de vida dos brasileiros e especificamente dos mineiros, belohorizontinos. Consideramos importante a visão dos alunos estrangeiros sobre a realidade brasileira, pois estes pertencem a outras culturas que podem ser diversas em alguns aspectos, mas similares em outros. A identidade nacional e cultural do aprendiz deve ser mantida, com ênfase nas trocas das experiências divididas e modos de ser diferentes (TROUCHE, 2005, p.75).

\section{$1^{\mathrm{a}}$ aula: Sociedade e personalidades}

Para a $1^{\mathrm{a}}$ aula iniciamos com uma atividade de quebra-gelo chamada Verdade ou Mentira, em que cada aluno deveria falar três sentenças sobre eles próprios e os outros alunos deveriam opinar se era verdade ou mentira. Após o quebra-gelo, utilizamos uma atividade que envolveu compreensão e produção oral. Distribuímos o texto 15 coisas ridiculas que os gringos dizem quando descobrem que você é brasileiro (a), em que são apresentados alguns enganos que os estrangeiros cometem ao conhecer um brasileiro, sobretudo os estereótipos. Logo após a discussão sobre o texto, os alunos assistiram a um vídeo intitulado If American tourists acted like Brazilians, em que dois rapazes americanos fingem ser brasileiros no Magic Kingdom, parque da Disney, em Orlando, e que serviu para abrir outra discussão, agora sobre a imagem que os estrangeiros têm do Brasil. Buscamos com essas atividades fazer uma relação da visão ou ideias que tinham do povo brasileiro e o que esperavam encontrar no Brasil, além de indagarmos sobre o que os estrangeiros pensam a respeito das pessoas e modos de vida ou costumes típicos de seus 
países de origem.

Para essa atividade houve a necessidade de uma troca de conhecimento de mundo; é preciso que o aprendiz estrangeiro perceba, ou melhor, compreenda o seu lugar no mundo, como ele próprio se vê e como é visto pelo outro e, ainda, como ele vê o outro (TROUCHE, 2005). Portanto, ao final da aula pedimos que escrevessem e compartilhassem com a classe a visão que tinham antes de chegar ao Brasil e as suas expectativas.

\section{$2^{a}$ aula: Comércio e transporte}

Nosso objetivo na segunda aula foi proporcionar o reconhecimento $\mathrm{e}$ aprofundamento de aspectos culturais, bem como a interação com pessoas da comunidade local, através do uso do transporte público - metrô e ônibus - além de uma visita guiada a um local específico. Adaptamos uma atividade retirada do PPPLE sobre transportes, cujo objetivo era mostrar, através de slides, quais são e como é o funcionamento dos meios de transporte belo-horizontino, seus horários, peculiaridades, como e onde utilizá-los, e ao mesmo tempo, através de informações dos alunos, estabelecer comparações de como funcionam os meios de transporte em seus países de origem e o comportamento das pessoas ao utilizá-los. Entendemos que é importante para o aprendiz recém-chegado esse conhecimento compartilhado sobre o "diferente" na língua e, consequentemente, na cultura estrangeira estudada. Para adquirir as competências comunicativas é preciso possibilitar ao aluno uma interação autônoma em situações reais de comunicação oral e/ou escrita. O contexto cultural do aluno interfere diretamente no processo de interpretação e de produção do texto ou da oralidade e de como agir na "nova" sociedade. (TROUCHE, 2005).

Assim, após a explicitação do assunto, comentários e respostas aos questionamentos, levamos os alunos para uma aula prática. Eles deveriam sair do Campus I e se dirigir à estação mais próxima de metrô - Estação Gameleira - comprar o bilhete, reconhecer as direções para descer na estação seguinte - Estação Vila Oeste - em direção ao destino proposto, o Campus II do CEFET/MG. Chegando lá deveriam fazer um tour de reconhecimento do Campus e voltar de ônibus, pela Av. Amazonas, para o Campus I. Toda essa atividade foi monitorada por nós, professoras, e por uma assistente. Essa atividade foi 
muito além do uso de transporte; os alunos entenderam como funcionam os meios de transporte em $\mathrm{BH}$ e também puderam perceber outros aspectos culturais: como o motorista e o pedestre agem no trânsito e como as pessoas se comportam ao usar o transporte público. Essa atividade também proporcionou a possibilidade de os alunos interagirem com as pessoas que utilizavam o transporte público.

\section{$3^{\text {a }}$ aula: Literatura, música, gastronomia}

De acordo com Kramsch (2008) é dever do professor de LE levar o aluno a ver o mundo por outros olhares, a se descobrir através de experiências reais, tácitas. O aprendiz de língua estrangeira precisa entender a maneira de agir e pensar do outro. Assim, para selecionar materiais e tarefas autênticas para alunos que estão no nível intermediário o ideal é deixar um pouco de lado temas abstratos, pois podem gerar dificuldade de entendimento. É melhor optar por segmentos orientados e curtos sobre cotidiano, estilo de vida e interesse pessoal, como esportes, músicas, danças etc.

Desta forma, buscamos para a terceira aula uma tarefa/atividade totalmente prática dentro do tema música. Ao invés de explicarmos ou aplicarmos atividades escritas para serem discutidas sobre os ritmos brasileiros mais conhecidos por eles, entramos em contato com uma dupla de experientes professores de dança que se propuseram a ensinar aos nossos alunos alguns passos iniciais de samba e forró. Ao final da aula, os alunos interagiram de forma intercultural mostrando na prática alguns passos de mambo e bachata, ritmos típicos de seus países. Nessa troca de "informações" que ocorreu de maneira bem espontânea e descontraída, o respeito e admiração a uma cultura diferente foram estabelecidos por ambas às partes. Nosso objetivo ao pensar essa aula foi sensibilizar os alunos às diferenças e semelhanças referentes a culturas rítmicas locais e brasileiras, através da dança, entendida aqui como uma manifestação explícita da cultura de um povo e até mesmo da maneira como escolhem se expressar.

\section{$4^{\mathrm{a}}$ aula: Regiões do Brasil (características geográficas, sociais, linguísticas)}

Segundo Trouche (2005), o ambiente instrucional de PLE transforma-se em lugar da construção de um conhecimento compartilhado e de aquisição de competência comunicativa quando as culturas brasileiras e estrangeiras, com seus aspectos sociológicos, antropológicos, históricos e artísticos, são engendradas na aula por meio de uma 
abordagem comunicativa, com seus componentes gramaticais, sociolinguísticos, discursivos e estratégicos. (apud. LEROY, 2011, p. 15).

Portanto, nesta aula optamos por abordar, de forma separada, a culinária mineira, tendo em mente que as tarefas dadas aos alunos estrangeiros devem ter um propósito social na comunidade linguística na qual são produzidas. É necessário não só ter a habilidade comunicativa na LE, mas também desenvolver a competência cultural na LE. Trabalhando com material autêntico, os alunos são levados a ter um comportamento social apropriado para cada ocasião, observando quem é seu interlocutor, qual seu propósito, o contexto no qual está inserido e as normas de interação na comunidade de falantes nativos. (KRAMSCH, 2008).

Com esse pensamento, após discussão da atividade dentro de sala sobre expressões típicas, utensílios e comidas preferidas dos mineiros, sempre em comparação com a culinária de seus países, levamos os alunos a um típico mercado local - próximo ao CEFET-MG - com uma grande variedade de produtos. Os alunos tinham uma lista de compras e deveriam marcar o que encontraram no mercado, bem como colocar o preço do produto ou ingrediente para dividir o valor da compra. Voltando à sala, eles deveriam montar uma salada tropical baseada em uma receita dada por nós. Precisariam, portanto, trabalhar em equipe ajudando a higienizar os alimentos, além de picá-los para a montagem final, para que pudessem degustar a salada em sala. Mais uma vez, nosso objetivo era propiciar novos questionamentos e entendimentos através de comparações não apenas entre a culinária estrangeira local e a de seu país de origem, mas da comparação de preços, de produtos, atendimento, etc. Por isso, a tarefa seguinte era levar e compartilhar uma receita típica de seus países de origem.

\section{$5^{\text {a }}$ aula: Brasil atual (tecnologia, educação, saúde)}

A partir do tema norteador decidimos explorar um pouco mais sobre aspectos musicais e usamos a sala de informática para uma aula prática sobre os ritmos brasileiros e sua história. Começamos com uma apresentação de slides, áudios e vídeos de vários ritmos e instrumentos típicos brasileiros de acordo com as cinco diferentes regiões do país (também discutidas). Assim, todos puderam aprender um pouco sobre os primeiros gêneros musicais trazidos pelos portugueses, índios e negros, desde 1500 até os dias atuais, no Brasil. Ao final da aula, os alunos acessaram o jogo musical Festival da Música Brasileira 
(online) em que puderam testar seus conhecimentos adquiridos nas aulas de dança e ritmos sobre a música popular brasileira. $\mathrm{O}$ site traz não só a explicação dos principais ritmos musicais brasileiros e seus principais compositores, como também um pequeno áudio para identificação do ritmo estudado.

Ao final da aula o aluno com maior pontuação ganhou um $\mathrm{CD}$, uma coletânea de Chico Buarque de Holanda. Nosso principal objetivo foi proporcionar uma visão geral da grande diversidade cultural do Brasil, deixando claro que a cultura e comportamentos mineiros são apenas um modo de vida dentre os vários existentes nessa extensão territorial brasileira absurda.

\section{AS AULAS DE CULTURA NA VISÃO DOS ALUNOS}

Antes de partimos para as respostas dos alunos ao formulário que elaboramos, gostaríamos de começar o relato com o $2^{\circ}$ momento da última aula do Módulo Cultura, pois foi onde retomamos a pergunta da aula inicial sobre o que pensavam sobre os brasileiros e o Brasil, mais precisamente Minas Gerais, e qual a ideia que tinham naquele momento, depois de quinze dias convivendo em imersão total com o povo belohorizontino. As perguntas foram: (i) quais impressões ainda eram as mesmas das impressões iniciais; (ii) quais eram completamente diferentes do esperado? Entre as respostas mais frequentes estavam as mais esperadas: a desconstrução dos estereótipos. Entre elas, o fato de o país não ser apenas samba e futebol. Descobriram que outros ritmos são apreciados, que nem todos os brasileiros sabem dançar samba, inclusive suas professoras. Acrescentaram que nem todos "respiram" futebol, e que existem outros esportes que são praticados e adorados pelos brasileiros. Perceberam que nem todos andam seminus nas ruas, pois as roupas dependem do clima local. Disseram ainda que há pessoas simpáticas e antipáticas, assim como em seus países de origem, dentre outros comentários.

Sendo assim, esta seção se propõe a relatar a opinião dos alunos dominicanos sobre o curso, especificamente sobre o Módulo Cultura, baseada em suas respostas ao questionário. A seguir algumas respostas - citações $\operatorname{diretas}^{1}$ e paráfrases - de forma resumida, a fim de apresentarmos um panorama geral da visão destes alunos, passando por

\footnotetext{
${ }^{1}$ As respostas dos alunos não sofreram nenhuma revisão ou correção.
} 
cada questão. Para preservar a identidade dos respondentes, utilizamos pseudônimos.

Questão 1. O que você achou das aulas de cultura, das atividades e tarefas dadas?

Percebemos aqui a satisfação de modo geral dos alunos em relação às aulas de cultura. Elogiaram a dinâmica das aulas e perceberam que elas foram personalizadas para o grupo deles, apesar do pouco tempo. Muitos citaram que conseguiram aprender mais sobre música brasileira, danças, culinária e os meios de transporte da cidade. Por exemplo, Laura respondeu da seguinte forma: "Eu gostei muito de todas as atividades. Aprendi sobre a música brasileira, os diferentes ritmos, as danças, os passos de baile. Também sobre a culinária e os médios de transporte na cidade". Juan disse que "eu acho que é um método muito bom (aulas de cultura, atividades e tarefas dadas) nos ajuda a descobrir o Brasil e a falar bem o idioma". Maria ressaltou que "gostei de tudo nas aulas, foram dinâmicas e muito personalizadas". E Laila finalizou "sobre as aulas de cultura, eu achei que foram muito bem impartidas para o pouco tempo que estivemos lá".

Questão 2. Essas atividades o auxiliaram na hora de aprender português?

Os alunos foram concisos em responder que, sim, as aulas auxiliaram no aprendizado da língua. Ana disse que "agora eu sei pegar o ônibus ou metrô e sei como devo fazer para pedir endereços e saber como chegar a um lugar. Também eu tenho melhorado muito na compreensão oral e auditiva”.

Questão 3. O fato de estar num ambiente de imersão ajudou?

Todos foram unânimes em responder positivamente.

Questão 4. Qual a ideia que você tinha da cultura do Brasil? E dos brasileiros?

Aqui foram destacados alguns aspectos de diversidade cultural brasileira, principalmente no que diz respeito à culinária e humor do povo brasileiro. Muitos afirmaram que já sabiam que as culturas eram próximas, ou parecidas em vários aspectos, outros ficaram surpresos com a grandeza, no sentido territorial, do Brasil e da grande diversidade da cultura brasileira. E alguns destacaram que imaginavam que o Brasil era só samba e pessoas alegres, mas isso foi desconstruído à medida que perceberam que as pessoas são pessoas comuns, com problemas e nem tudo é carnaval. Laura expressou-se dizendo que "já conhecia bastante da cultura brasileira porque eu tenho amigos brasileiros na República Dominicana. Para mim eles são pessoas muito agradáveis e amistosas, como 
a maioria dos dominicanos. E a culinária é muito parecida a culinária dominicana”. Juan disse "[é] uma cultura muito diversa, os brasileiros, gente muito legal, alegre e agradável". Pode-se perceber a admiração nas palavras de Maria ao dizer "tão grande é o Brasil, tão grande é a sua cultura! A diversidade da paisagem, do clima, das comidas, etc. fazem do Brasil um país muito atraente. Eu não posso dar muita informação sobre brasileiro porque não é facil para descrever pessoas como nós pode fazêlo para a natureza. Especialmente no Brasil há várias categorias de pessoas, mas basicamente podemos dizer que o Brazil é uma nação que é muito acolhedor, que está ligado á sua cultura". E Ana demonstra ter mudado de ideia sobre os estereótipos brasileiros: "pensava Brasil era sozinho samba e pessoas alegres, descobri que são pessoas comuns com problemas e alto conhecimento de cultura geral que não é sozinho carnaval".

Questão 5. A ideia que você tinha em relação à cultura brasileira foi confirmada? Comente.

Aqui pontuaram que algumas coisas confirmaram suas ideias, tais como a boa comida, pessoas agradáveis que gostam de conversar e fazer amigos, no entanto, outras ideias, como a do samba ser o único ritmo do Brasil, foram mudadas, pois conheceram o forró, frevo, dentre outros. Laura respondeu afirmativamente "si, sobre tudo com as comidas gostei muito e era o que esperava". Juan disse que "sim, as pessoas são amáveis e gostam muito de sair aos lugares para conversar e compartilhar com os amigos". Maria enfatizou que "o Brasil possui muito do que eu imaginava, por exemplo, fala apenas de "Samba", como dança, em contrapartida, há outros muito famosos, como Forró, Frevo Capoeira etc". E Ana concordou dizendo "sim, o Brasil é um pais grande, com muita diversidade cultural".

Questão 6. Você considera importante a presença da cultura no ensino de idiomas? Por $q u \hat{e} ?$

Podemos citar algumas respostas sem interpretá-las, como a da Laila: "sim, em minha opinião, ela [a cultura] é muito importante. É melhor experimentar a cultura dentro da mesma cultura". Juan disse "passar vários dias dentro da cultura ajuda a compreendê-la e a compará-la com sua própria cultura". Maria, por sua vez enfatizou: "considero, sim, a cultura é a essência dos povos e a base de seus idiomas". Ana lembra "sim, sim, é muito importante à introdução da cultura na aprendizagem [...] nos permite conhecer ou aprender a língua melhor". E Laura conclui dizendo "sim [...] com esse método aprendi muitas 
palavras".

Questão 7. Como você gostaria ou imagina que deveriam ser as aulas de cultura num ambiente de imersão?

Neste tópico, Juan sugeriu que as aulas sempre devem ser "interativas e participativas". Ana disse que "devem ser sempre práticas. Para entender a cultura você tem que viver dentro de essa cultura. Experimentala pessoalmente". Laura enfatizou, ainda, que "devem agregarle de início a orientação dos meios de transporte porque um chega desubicado e séria de muita ajuda". Além disso, Maria ressaltou que "ensinar uma língua em um ambiente cultural diferente já é muito interresante, podemos fazer excursões, passeios em grupo (restaurante, dança, atração, etc)"'.

Questão 8. Na sua opinião, o que poderia ser alterado no curso de cultura brasileira? $O$ que se deveria privilegiar?

Separamos partes das respostas mais recorrentes: Ana, por exemplo, disse "se deve privilegiar o contato direito com os brasileiros, sair a conversar com eles, estudar com eles e fazer atividades juntos. Eu acho que nós fizemos muitas atividades assim nesse curso, eu estou muito satisfeita por isso". Juan deu a seguinte sugestão: "ensinar uma língua, em particular a sua própria língua, é sempre bom para promover seu território, valorizando as coisas mais belas do país. Mas como uma sugestão é sempre bom saber algumas coisas sobre outros países também". E Maria sugeriu "eu creio devem agregar mais cursos de ensino das conjugações dos tempos verbais e mais visitas aos museus".

Questão 9. Conhecer melhor a cultura brasileira dentro de Belo Horizonte lhe ajudou a compreender sua própria cultura? Se sim, explique.

Mais uma vez, deixemos que os próprios alunos respondam: Laura concordou dizendo "sim, eu pude fazer uma comparação entre a cultura brasileira e a cultura dominicana, e eu achei que somos muito parecidos, em especial no temperamento alegre e amistoso, e no gosto da música e da culinária". Ana apontou "certamente sim, ele me ajudou a conhecer melhor agora e entender a cultura do meu país. Por exemplo, em casa no Haiti há pessoas no norte (Cap Haitien), falam muito diferente de outros lugares (acento e alguns vocabulários). E é o mesmo caso no Brasil em algumas localidades". Laila afirmou 
que "sim, conhecer outras culturas sempre ajuda a conhecer a si próprio, porque ambas as culturas são muito parecidas desde os tempos da colonização”. E Juan completou dizendo que "ajudou-me a entender o porquê do parecido de ambos os países".

Questão 10. Você voltaria ao Brasil para fazer outro curso avançado de língua portuguesa e cultura brasileira? Se sim, quais tópicos, assuntos ou temas gostaria que fossem abordados?

Finalmente, todos disseram que voltariam e alguns gostariam de conhecer outros estados para conversar com mais pessoas, como disse Laila "se eu tiver que voltar ao Brasil para fazer outro curso avançado de língua portuguesa e cultura brasileira, eu gostaria de visitar outro Estado, falar com mais gente, e contar tudo, porque Português do Brasil tem muito a ouvir e muito a dizer". Outros expressaram desejo de aprender mais sobre gramática, conjugação verbal, pronúncia nasal, e ainda, como Juan afirmou "sim, eu voltaria! Eu gostaria que fossem abordados mais temas de literatura brasileira, cinema e sociedade".

A seguir faremos nossa própria reflexão a respeito das aulas e atividades que ministramos, buscando uma visão geral do módulo, no intuito de apontarmos coisas positivas e coisas que ainda podem ser trabalhadas dentro da abordagem intercultural.

\section{AS AULAS DE CULTURA NA VISÃO DOS AUTORES}

Ter a oportunidade de trabalhar em um ambiente de imersão com alunos que possuem um perfil basicamente homogêneo em relação à origem, idade, grau de escolaridade, objetivo e conhecimento na língua alvo, no caso português em nível intermediário, nos possibilitou um "leque" maior de opções ao se pensar em trabalhar a cultura brasileira e a local, no caso, a mineira, dentro da abordagem intercultural. Desta forma, decidimos elaborar tarefas autênticas e comunicativas que possibilitassem a inserção desses aprendizes na sociedade local e que, sob a orientação das professoras, os levassem a vivenciar a "nova" cultura, favorecendo o reconhecimento das semelhanças e diferenças entre as culturas nativas e a cultura alvo, aprimorando, assim, cada vez mais a língua portuguesa.

Nas palavras de Mendes (2015, p. 218) a cultura "engloba uma teia complexa de significados", os quais só podem ser interpretados por aqueles que fazem parte de uma 
mesma realidade social. Portanto, a cultura "não existe sem uma realidade social que the sirva de ambiente". Com essa visão em mente, e após refletir sobre as atividades e tarefas realizadas com esse grupo de alunos neste curso específico, percebemos que o fato de estar em um ambiente de imersão favoreceu, logicamente, não só o aprendizado da língua portuguesa, mas também o aprendizado de parte da cultura brasileira, aqui entendida não só como a história, literatura, etc. de uma determinada sociedade, mas como os valores, crenças, modo de pensar, de agir e reagir a situações diversas que cada povo possui. Percebemos que as tarefas desenvolvidas possibilitaram aos aprendizes uma reflexão sobre suas línguas e culturas maternas e a partir daí puderam entender melhor a língua e a cultura estrangeira. Além disso, a comparação constante entre as duas culturas colaborou para que desenvolvessem uma visão crítica, ajudando-os a aceitar o diferente e estabelecendo uma atitude positiva de compreensão das diversidades culturais, ou seja, uma imagem de respeito e valorização da nova cultura e da cultura nativa. É isso que consideramos interculturalidade e identidade cultural.

Finalmente, através das respostas dos alunos ao questionário realizado para este estudo, percebemos que as aulas possibilitaram maior segurança na hora de se comunicarem e interagirem com as pessoas na comunidade, além do aprimoramento da desenvoltura para lidar com situações cotidianas, como comprar uma passagem de ônibus, fazer pedidos em um restaurante ou lanchonete, realizar compras em mercados, usar o transporte público, etc. No entanto, estamos conscientes que em um curso intensivo como esse, de apenas quinze dias, não é possível abarcar todos os tópicos ou temas equitativamente e de forma diversificada. O fator tempo, em sala e fora dela, é fundamental se pensarmos que o ideal, ao se trabalhar cultura, seria proporcionar (i) momentos de preparação para as atividades extraclasse, (ii) um tempo maior no desenvolvimento das tarefas práticas, pois os encontros fora de sala costumam ser demorados e pode haver imprevistos, e (iii) após a execução das tarefas, voltar para sala de aula a fim de retomar os temas trabalhados através de comentários e/ou discussões, para que a troca de experiências, comparações entre os conhecimentos culturais maternos e adquiridos se construam de maneira efetiva.

\section{CONSIDERAÇÕES FINAIS}

Neste artigo, procuramos refletir sobre o ensino de PLE através de uma abordagem 
interculturalista num ambiente de imersão. Para isso, relatamos o desenvolvimento do Módulo Cultura de um dos cursos para estrangeiros no CEFET-MG e fizemos um estudo das atividades, tanto as que aconteceram em sala de aula, como as aulas externas do Módulo, a fim de apontar possibilidades para o ensino de língua e cultura.

Lecionar uma LE e seus aspectos culturais não é um processo tão simples, tendo em vista que língua e cultura estão relacionadas e que a sala de aula de PLE é um espaço de diálogos entre culturas, expressões, etc. Além disso, a ligação entre uma língua e a comunidade usuária dessa língua pode variar muito. No entanto, o homem se constitui na cultura, portanto, o contexto cultural é fundamental para a compreensão da língua estrangeira. Tentamos, através das atividades desenvolvidas com os aprendizes, dar oportunidade ao aluno estrangeiro para refletir criticamente sobre a realidade brasileira (local) no intuito de diminuir a dificuldade na captação dos sentidos, dos valores e das diversas formas de agir do belo-horizontino, em especial, e assim, levá-lo a um momento de reflexão entre a cultura nativa e a 'nova' cultura.

Sabendo que o trabalho de escolha dos materiais e tarefas autênticos é responsabilidade do professor, seja qual for o tema, procuramos auxílio no Portal do Professor de PLE e elaboramos materiais específicos a esse grupo de estudantes da República Dominicana e Haiti, pois acreditamos que:

\footnotetext{
"A questão que surge pelo uso de materiais da vida real é que a cultura é uma realidade que é social, política e ideológica e que a dificuldade de entendimento dos códigos culturais se origina da dificuldade de ver o mundo de uma perspectiva diferente, não do entendimento de outro código lexical ou gramatical. " (KRAMSCH, 2008, p.188).
}

Diante desses apontamentos, mesmo sendo um trabalho muito específico, esperamos que essa reflexão contribua como inspiração para novas ideias e debates acerca da elaboração e aplicação de tarefas comunicativas e autênticas que possam fazer parte das aulas de cultura no ensino de PLE, dentro de um ambiente de imersão; e que tais tarefas sejam moldadas dentro da abordagem intercultural, em que língua e cultura são vistas como indissociáveis, e os aspectos identitários sejam valorizados em ambas as culturas. Acreditamos que, para um aprendizado efetivo da língua e cultura alvo, o aprendiz deve ser levado a explorar a cultura in loco e presenciar e/ou participar de situações reais vividas pelas pessoas que fazem parte da sociedade na qual está inserido. Finalmente, baseados em nossa experiência, consideramos essencial a interação em sala e os momentos de trocas de 
experiências e autoquestionamento sobre a cultura local e a do aprendiz, para que haja uma melhor compreensão cultural e respeito mútuos.

\section{REFERÊNCIAS}

ÁLVARES, M. L. O. Políticas de Difusão e formação crítica em PLE: por uma formação por competências. In: MENDES, E. Diálogos Interculturais Ensino e formação em português língua estrangeira. Campinas, Pontes, p. 173-205, 2011.

ANDRIGHETTI, G. H. \& SCHOFFEN, J. R. Vivenciando língua e cultura: sugestões para práticas pedagógicas em Português como língua Adicional. In: SCHOFFEN, J. R., KUNRATH, S. P., ANDRIGHETTI, G. H., SANTOS, L. G. dos. Português como língua adicional: reflexões para a prática docente. Porto Alegre: Bem Brasil, p. 17-44, 2012.

Educar para Crescer. Festival da Música Brasileira. Disponível em: http://educarparacrescer.abril.com.br/mpb/. Acesso em: julho de 2015.

FRANÇA, J. L.; VASCONCELOS, A. C. de A. G. Manual de Normatização de Publicações Técnico-científicas. Belo Horizonte: Ed. UFMG, 2009.

FERREIRA, I. A. Perspectivas interculturais na sala de aula de PLE. In: SILVEIRA, R. C. P. da (org.). Português língua estrangeira perspectivas. São Paulo: Cortez, p. 39-58, 1998.

JÚDICE, N. Seleção e abordagem de fotografias, cartuns e quadrinhos no ensino da língua e da cultura do Brasil para estrangeiros. In: JÚDICE, N. Ensino da Língua e da Cultura do Brasil para Estrangeiros. Niterói: Intertexto, p. 31-51, 2005.

KRAMSCH, C. Authentic texts and contexts. In: KRAMSCH, Claire. Context and Culture in Language Culture. Oxford University Presss, p. 177-204, 2008.

LEROY, H. R. Ensino de Língua Portuguesa para estrangeiros em contextos de imersão e de não imersão: percepções interculturais dos aprendizes e do professor. Dissertação de Mestrado inédita, 2011. Disponível em: www.posling.cefetmg.br.

PPPLE. Portal do Professor de Português como Língua Estrangeira. Disponível em: http://www.ppple.org. Acesso em: junho de 2015.

MENDES, E. A ideia de cultura e sua atualidade para o ensino-aprendizagem de LE/L2. Entre Línguas, Araraquara, v.1, n.2, jul./dez., p. 203-221, 2015.

MENDES, E. O português como língua de mediação cultural: por uma formação intercultural de professores e alunos de PLE. In: MENDES, E. Diálogos Interculturais Ensino e formação em português língua estrangeira. Campinas, Pontes, p. 139-158, 2011. 
The Florida Men. If American tourists acted like Brazilians. Disponível em: https://www.youtube.com/watch?v=LZYBpN0VkVk. Acesso em: junho de 2015.

TROUCHE, L. M. G. Leitura e interpretação: inferências socioculturais. In: JÚDICE, N. (org). Ensino da Língua e da cultura do Brasil para Estrangeiros. Niterói: Intertexto, p. 69-80, 2005.

\section{OS AUTORES}

Fernanda Ricardo Campos é Mestre em Estudos de Linguagens pelo CEFET-MG (2016), especialista em Leitura e Produção de Textos pela UFMG (2009) e graduada em Letras pela PUC-MG (2007). Foi professora do CEFET-MG, Leitora de Língua Portuguesa e Cultura Brasileira do MRE, na Universidade Nacional Mayor de São Marcos em Lima/Peru e colaboradora do Centro Cultural Brasil-Peru e do Setor Cultural da Embaixada do Brasil em Lima/Peru. Possui experiência na aplicação e correção do exame CELPE-BRAS. É integrante dos grupos de pesquisa Infortec e do Grupo de Pesquisa em Materiais e Recursos Didáticos, ambos do CEFET/MG. Atualmente é revisora de textos do Colégio Sagrado Coração de Maria-BH.

E-mail: nanda.ricardo@gmail.com

Jerônimo Coura-Sobrinho possui graduação em Letras (Francês e Suas Literaturas) pela UFMG (1994), graduação em Licenciatura Plena Para a Graduação de Professores pelo Centro Federal de Educação Tecnológica de Minas Gerais (1990), graduação em Engenharia Civil pela Escola de Engenharia Kennedy (1980), graduação em Letras (Inglês/Português e Suas Literaturas) - Faculdades Metodistas Integradas Isabela Hendrix (1986), mestrado em Letras (1998) e doutorado em Estudos Linguísticos (2004) pela UFMG. Atualmente é professor da educação básica técnica do CEFET-MG. Tem experiência na área de Linguística, com ênfase em Análise do Discurso, atuando como avaliador do exame Celpe-Bras, no ensino de português para estrangeiros.

E-mail: jeronimocoura@gmail.com

Rose Mara Silva é mestranda no Programa de Pós-Graduação em Estudos de Linguagens e Tecnologia do CEFET-MG. Possui especialização em Língua Inglesa (2004) e graduação em LETRAS (2001) pela Universidade do Estado de Minas Gerais. Atualmente, atua como Educador II efetivo de Língua Inglesa no Município de Divinópolis-MG. É integrante do grupo de pesquisa Infortec-Núcleo de Pesquisa em Linguagens e Tecnologia do CEFETMG. Ministrou o Curso Intensivo de Língua Portuguesa e Cultura Brasileira para Estrangeiros (2015 e 2016) e possui experiência na aplicação da Parte Oral do Exame de Certificação de Proficiência em Língua Portuguesa para Estrangeiros - CELPE-BRAS como entrevistadora e avaliadora do exame.

E-mail: stephrosie@hotmail.com 